\title{
Turkic default agreement
}

\author{
Deniz Satı*
}

\begin{abstract}
Baker \& Vinokurova (2010) argue for a hybrid account of morphologically observable case, which involves both a configurational theory for accusative and dative, as in Marantz (1991), and case assignment by functional heads for nominative and genitive, as in Chomsky (2001). In the spirit of Levin \& Preminger (2015), I argue that a configurational theory is enough to account for the assignment of genitive case. Based on the understudied phenomenon of default agreement with complex possessors in Turkic, I argue that a configurational theory is better equipped at handling the distribution of genitive case. I present a phase-based account of case blocking agreement in order to derive default agreement.
\end{abstract}

Keywords. turkic; turkish; default; agreement; case; genitive; nominative

1. Introduction. Baker \& Vinokurova (2010) (B\&V) and Baker (2015) present a two-modality approach to case assignment, in which different cases may be assigned in one of two ways: either configurationally, as in Marantz (1991), where case is assigned depending on its location and its relationship with other nominals in its domain, or assigned via agreement with functional heads, as in Chomsky (2000). In particular, they argue that the agreement of nominative and genitive case cannot be assigned configurationally based on agreement patterns in Sakha, a Turkic language, although accusative and dative are assigned in this manner.

In the spirit of Levin \& Preminger (2015), I argue that positing two different modalities of case is not necessary. I provide two novel empirical arguments for genitive case being assigned as an unmarked case (and, by extension, nominative) not just in Sakha, but other Turkic languages as well. The first argument is the presence of morphologically unmarked pronouns (nominative) in Turkic partitive subjects, such as (biz) iki-miz 'the two of us,' where the pronoun is optional, but the nominal agreement in bold on the head numeral iki is not. Contrary to fact, agreement would assign genitive case to this pronoun inside the partitive subject under B\&V's approach. I argue that this can be accounted for if genitive case is assigned configurationally.

Second, I introduce the problem of Turkic default agreement, which has received very little attention in the literature in the case of Turkish, and not discussed at all for other Turkic languages. ${ }^{1}$ In Turkic default agreement, complex possessors such as partitive subjects and adnominal pronoun constructions (APCs, ex. 'we Turks') agree fully in finite clauses with matrix verbs, but do not agree with head nouns in simple possessive structures, relative clauses and elsewhere; in other words, when they receive genitive case in Turkic. ${ }^{2}$ In these cases, full agreement, 1PL, is not permitted, and default agreement, 3SG is required, as in (1a)-(1d):

\footnotetext{
* Thanks to Jonathan Bobaljik, Omer Preminger, Susi Wurmbrand, audiences at Tu+5 and my Universals talk for helpful comments. Thanks to Maria Ostanina, Daria Boltokova and others for data in Altai, Uzbek, Sakha and Kyrgyz. I am grateful to my parents, among others, for data from Turkish. Authors: Deniz Satık, Harvard University (deniz@g.harvard.edu)

${ }^{1}$ The data that will be presented in this paper is from several Turkic languages: Turkish, Kyrgyz, Sakha, Uzbek and Altai. The Turkish data was obtained through native speaker judgments from three different speakers, including myself, while the Kyrgyz, Altai, Sakha and Uzbek data was obtained from at least a single native speaker consultant for each, either in person or by Skype, and much of this was supplemented with data from the literature.

${ }^{2}$ Other elements also trigger default agreement: reflexives such as kendi and inflected pronouns such as sizler 'you guys,' glossed as 2PL-PL. Inflected pronouns are likely adnominal pronouns, but with a null noun meaning something like 'people.' I provide potential accounts of these in the conclusion.
} 

a.
(Biz) iki-miz-in
kedi-si
c. $*(\mathrm{Biz}) \mathrm{iki}$-miz-in
kedi-miz
(1PL) two-POSS.1PL-GEN cat-POSS.3SG 'the cat that belongs to the two of us'
(1PL) two-POSS.1PL-GEN cat-POSS.1PL 'the cat that belongs to the two of us'
b. biz Türk-ler-in kitab-ı
d. * biz Türk-ler-in kitab-1mız
1PL Turk-PL-GEN book-POSS.3SG
'the book that belongs to us Turks'
1PL Turk-PL-GEN book-POSS.1PL 'the book that belongs to us Turks'

However, in all other Turkic languages, I present novel data to show that default agreement with complex possessors is merely optional, and banned in Uzbek. To account for this, I provide an account of default agreement based on Chomsky (2001)'s weakened Phase Impenetrability Condition and the assumption that case, blocks agreement. A similar observation has been made in Hungarian and Finnish in the unpublished Holmberg (2017), who also argues that case is responsible for blocking agreement; in Hungarian in particular, dative-case marked complex possessors also force default agreement on the head noun.

\section{Background.}

2.1. TwO THEORIES OF CASE. The theory of case that this paper will argue against, at least for the assignment of genitive case, is one in which case assignment is a consequence of agreement. ${ }^{3}$ Case is assigned to a noun phrase, NP, that is local to its probe, a functional head $\mathrm{F}^{0}$. If $\mathrm{F}^{0}$ c-commands NP and is able to find an NP in its search domain to assign case to. According to Baker \& Vinokurova (2010) (B\&V), this case assignment is parasitic on the simultaneous $\phi$ feature agreement between $\mathrm{F}^{0}$ and NP. If there is no agreement, there is no case assignment.

I will argue that the assignment of genitive case is best captured under the configurational case approach, in which different cases are assigned based on whether there are other nominals in the same local domain. Marantz (1991) defines four kinds of case in the following hierarchy: ${ }^{4}$

(2) Case realization disjunctive hierarchy (top to bottom)

a. Lexical/oblique case: case determined by the lexical properties of an item. Ex. quirky case in Icelandic

b. Dependent case: assigned depending on the relationship between nominals in some domain. Ex. accusative and ergative

c. Unmarked case: case assigned automatically to any NP in a clause (nominative/absolutive) or any NP in an NP/DP (genitive)

d. Default case: assigned to any NP left unmarked for case

Some authors, such as B\&V and Baker (2015), have argued that both of these methods of assigning case exist crosslinguistically, and in some cases even in the same language, such as Sakha. Both argue that nominative and genitive case assignment cannot be accounted for in the Marantz (1991) approach, because nominative and genitive case appear only when a verb or a determiner respectively agrees with them..$^{5}$ Some of their evidence is given in (3a)-(3b), which are ruled out

\footnotetext{
${ }^{3}$ This paper is concerned only with morphologically observable case, in the sense of the distribution of morphological forms of nominals, rather than abstract case-licensing; see Marantz (1991) on whether abstract case exists.

${ }^{4}$ Unmarked case is not to be confused with morphologically unmarked case; notice that the genitive is often morphologically marked crosslinguistically. These are separate notions.

${ }^{5}$ For our purposes, I will focus only on how the genitive case is assigned in Sakha, which B\&V argue is assigned by agreement via functional heads. However, they argue that accusative and dative case are both assigned under the configurational case approach as a form of dependent case.
} 
because in the absence of nominal agreement, genitive case cannot be assigned.

a. Aisen aqa-*(ta)

Aisen father-*(POSS.3SG)

'Aisen's father.'

b. Masha terilte-ni salaj-yy-*(ta)

Masha company-ACC manage-EV.NOML-*(POSS.3SG)

'Masha's managing the company.'

(Baker \& Vinokurova 2010; p. 634)

But as Levin \& Preminger (2015) point out, we could assume that agreement itself is parasitic on case and derive the same results, following Bobaljik (2008). According to Bobaljik, case is assigned configurationally. Agreement looks for case-marked nominals and the appropriateness of the target obeys the Revised Moravcsik Hierarchy, which is as follows: unmarked case $\gg$ dependent case $\gg$ oblique case. $^{6}$

Only the unmarked cases, nominative and genitive, are accessible to agreement in Turkish and Sakha. Rather than saying case is parasitic on agreement, we could provide Levin \& Preminger (2015)'s account of agreement in Sakha under the configurational case theory, in which the probes $\mathrm{T}^{0}, \mathrm{D}^{0}$ or Poss ${ }^{0}$ will search their c-command domains for a nominal bearing unmarked case and agree with it. A final assumption I want to make is that nominative case is just caselessness, following Bittner \& Hale (1996) and Kornfilt \& Preminger (2015) among others, who argue that unmarked case is best represented as having no proper grammatical representation.

2.2. Default agreement with complex possessors. This phenomenon is not unique to Turkish or the Turkic languages. In an unpublished manuscript, Holmberg (2017) attempts to come up with an account of default agreement in Finnish and Hungarian, although he does not refer to it as default agreement. He notes that the pronoun in the adnominal pronoun construction (APC) does not reflect the case assigned to the entire pronoun; for example, in the possessive structures below, the possessive clitic must attach to the entire APC, and not the determiner which heads the possessor:

(4) a. * your children opinions

b. ? you children's opinions

He notes that this possible in Finnish, however. First, he points out that Finnish has APs:

$$
\text { Me lapset voi-mme tulla mukaan }
$$

we.NOM children.NOM can-1PL come along

'We children can come along.'

Importantly for our purposes, he notes that in a possessive construction in which the possessor is an adnominal pronoun, there cannot be agreement on the head noun; in Finnish the null form of the noun is the 3rd person singular form, as seen in (6a)-(6b). This is despite normal possessive structures in Finnish having obligatory or optional agreement, depending on the dialect, as in (6c). In addition, the pronoun of the AP has genitive case in (6a)-(6b):

\footnotetext{
${ }^{6}$ But for the purposes of this paper, I remain agnostic on agreement being postsyntactic. Though Bobaljik claims case and agreement are postsyntactic, I need not assume this in the paper. See Preminger (2014) for an account in which agreement and case assignment are both syntactic.
} 

a. teidän lapsien mielipitee $(*$-nne)
you.GEN children.GEN opinions.3SG-(*2PL)
'you children's opinions'
b. Meidän lapsien mielipiteitä(*-mme) ei oteta vakavasti.
we.GEN children.GEN opinions.PAR.3SG(*-1PL) not take.PASS seriously
'We children, our opinions are not taken seriously.'
c. teidän mielipitee-nne
you.GEN opinions-2PL
'your opinions'

How do we account for there being default agreement only with genitive case-marked APCs? An intuitive answer is to rely on the KP layer projected by the genitive case blocking agreement, and indeed, this is Holmberg's answer. The nominative does not project a KP layer according to this account. In the tree below, KP, which blocks agreement, is circled in gray:

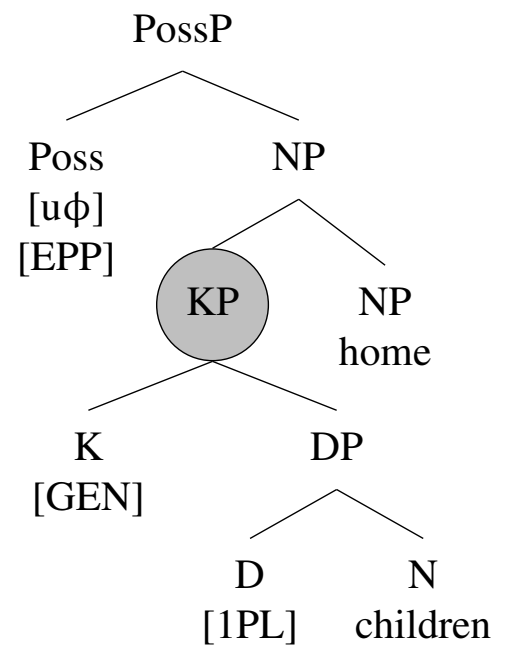

In a nutshell, Holmberg proposes that KP blocks access to the $\phi$-features of the pronoun, but the derivation does not crash and default agreement arises on the head noun. But this has the obvious problem of deriving default agreement even with genitive case-marked regular pronouns; Holmberg does not address this problem. Both regular and adnominal pronouns must be casemarked, or in other words project KPs; Holmberg seems to suggest only APCs project KPs.

Even so, evidence for the KP-account is seen in Holmberg's evidence from Hungarian, which has dative-marked possessors. Hungarian allows two kinds of possessive constructions, one in which the possessor is morphologically unmarked and the possessor follows the definite article, and another in which the possessor is dative-marked and precedes it:

$$
\begin{aligned}
& \text { a. a ti vélemén-ye-tek } \\
& \text { the you opinion-POSS-2PL } \\
& \text { 'your opinion' }
\end{aligned}
$$
b. nektek a vélemén-ye-tek you.DAT the opinion-POSS-2PL 'your opinion'

Dative case-marking blocks agreement with adnominal pronouns, as seen in (9): ${ }^{7}$

\footnotetext{
${ }^{7}$ APCs are marginally possible with dative case-marked possessors in Hungarian, but not possible at all with bare possessors. Dative-marking is present on both the possessor and the pronoun, like Finnish.
} 
? csak nektek gyerekeknek a véleménye $(*$-tek) befolyásolja a döntésünket. only you.DAT children.DAT the opinion(*-POSS.2PL) influences the decision.ACC 'It's only you children's opinion that influences our decision.'

This provides us reasons to assume that agreement itself is parasitic on case. ${ }^{8}$

\section{Turkic default agreement and partitive subjects.}

3.1. DATA. Turkic default agreement occurs on head nouns with complex possessors like partitive subjects, for example (biz) iki-miz 'the two of us,' and adnominal pronouns, for example biz Türkler 'we Turks.' ${ }^{9}$ In the case of adnominal pronouns, the pronoun cannot be dropped, as in (10a). This is perhaps due to competition with the generic plural Türkler 'Turks,' which cannot mean we Turks; unagreement is not possible.

On the other hand, the partitive subject construction (partitive) does have the possessive suffix on the numeral; this could indicate that there is agreement between the pronoun in the partitive and the numeral. Furthermore, only numerals can be the head noun in the partitive. An example of the partitive is given in (10b). These examples also show that full agreement is required in simple finite clauses, because the removal of the 1 st person verbal agreement $-k$ would lead to there being 3rd person agreement on it instead as it is null:
a. $\quad *($ Biz) Türk-ler kazan-d1-*(k)
*(1PL) Turk-PL won-PST-*(1PL)
'We Turks won.'
b. (Biz) iki-miz kazan-d1-*(k)
(1PL) two-POSS.1PL won-PST-*(1PL)
'The two of us won.'

However, the pronoun in the partitive is usually dropped, ex. iki-miz 'the two of us.' I assume that it is always present but optionally null for two reasons: the $\phi$-features on the possessive suffix have to come from somewhere-likely from a null pronoun in the partitive, as Turkish is a famous pro-drop language-and because in any context with a partitive, a pronoun can optionally be pronounced overtly, perhaps for emphasis purposes.

Nominal agreement on a bare pronoun in a partitive is unpredicted by Baker's analysis of genitive case assignment in Sakha, given that it would predict the partitive pronoun to have genitive case rather than nominative. A Poss ${ }^{0}$ under Baker's analysis should always assign only genitive case, but we see that it is bare; *biz-im iki-miz is ungrammatical as a partitive subject.

However, full agreement is never possible with complex possessors; this leads to default agreement, perhaps due to the presence of genitive case. This is shown in (11) below.
a.
(Biz) iki-miz-in
kedi-si c.
c. Biz Türk-ler-in günah-lar-1
(1PL) two-POSS.1PL-GEN cat-POSS.3SG
1PL Turk-PL-GEN sin-PL-POSS.3SG
'the two of us's cat' 'the sins of us Turks'
b. *(Biz) iki-miz-in
kedi-miz
d.
(1PL) two-POSS.1PL-GEN cat-POSS.1PL 'the two of us's cat'
* Biz Türk-ler-in günah-lar-1mız 1PL Turk-PL-GEN sin-PL-POSS.1PL 'the sins of us Turks'

\footnotetext{
${ }^{8}$ An anonymous reviewer suggests that focus, rather than case, is what is responsible for bleeding agreement in Hungarian. This may be correct, but as the reviewer points out, this would not be problematic to the premise of this paper, as I claim later on that focus may also bleed agreement.

${ }^{9}$ Default agreement with partitive subjects (but not adnominal pronouns) in Turkish was previously discussed in the unpublished Ince (2008) and Aydın (2008). I have extended this to other Turkic languages, in addition to new data from Turkish default agreement, and a novel account of Turkic default agreement.
} 
This is not unique to simple PSes; there are many other contexts in the Turkic languages in which genitive case is assigned. I give examples from several constructions in (12) below; full agreement is impossible in each of these:
a. Iki-miz-in ye-diğ-i döner
two-POSS.1PL-GEN eat-FN-POSS.3SG doner
'the doner the two of us ate'
Relative clause
b. Zeynep iki-miz-in gel-me-si-ni isti-yor.
Zeynep two-1PL-GEN come-INF-3SG-ACC want-PRES
'Zeynep wants the two of us to come.'
Inflected infinitival clauses
c. Zeynep iki-miz-in gide-ceğ-i-ni söyle-di.
Zeynep two-1PL-GEN go-FUT-POSS.3SG-ACC said-PST
'Zeynep said the two of us will go.'
Nominalized clauses

With this background in mind, we can now consider an independent argument for the opacity of genitive case-marked adnominal and partitive pronouns being opaque for agreement. Kornfilt (2003) points out strong evidence in favor of this, based on an asymmetry between argument and adjunct nominalized clauses. She points out that the subjects of factive nominalized clauses must be nominative if the clause is an adjunct, as shown in (13b):

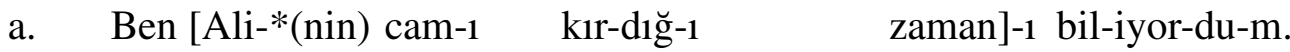
I Ali-*(GEN) glass-ACC break-FN-POSS.3SG time-ACC know-PROG-PST-1SG 'I knew when Ali broke the glass.'

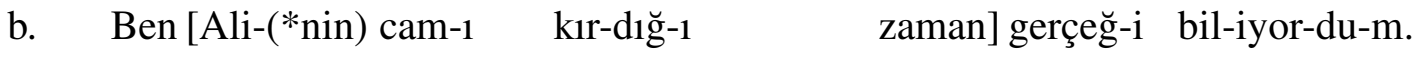

I Ali-(*GEN) glass-ACC break-FN-POSS.3SG time truth-ACC know-PROG-PST-1SG 'I knew the truth when Ali broke the glass.'

In these factive nominalized adjuncts, the subject must be nominative; it cannot be genitivemarked, and it triggers full nominal agreement, as shown in (14a). The partitives and APCs show the same pattern in (14b), but they never trigger default agreement, as seen in (14c). This indicates the opacity of these elements, when marked with the genitive, to agreement.

a. [[Biz- $(*$ im) yemek pişir-diğ-imiz]-den dolay1] konser-e gid-e-me-di-m. 1PL-(*GEN) food cook-FN-POSS.1PL-ABL because concert-DAT go-ABIL-NEG-PST-1SG 'Because we cooked, I was unable to go to the concert.'

b. [[Iki-miz- $(* i n)$ yemek pişir-diğ-imiz]-den dolay1] konser-e gid-e-me-di-m. two-1PL- $\left({ }^{*} \mathrm{GEN}\right)$ food cook-FN-POSS.1PL-ABL because concert-DAT go-ABIL-NEG-PST-1SG 'Because the two of us cooked, I was unable to go to the concert.'

c. * [[Iki-miz yemek pişir-diğ-in]-den dolayı $]$ konser-e gid-e-me-di-m. two-1PL food cook-FN-POSS.3SG-ABL because concert-DAT go-ABIL-NEG-PST-1SG 'Because we cooked, I was unable to go to the concert.'

We now move on to discuss the different properties of Turkic default agreement. Aydin (2008) argues that default agreement is always optional in finite clauses, based on his sentence below where the partitive is paired with sadece 'only':

\footnotetext{
Sekizkişi paintball-a git-miş-ti-k ve sadece iki-miz daha-önce oyna-mış-tı(-k) Eight person paintball-DAT go-EV-PST-1PL and only two-1PL before play-EV-PST-(1PL) 'Eight of us went to play paintball and only two of us had played before.'
} 
Default agreement is not optional in the much simpler counterpart (10b), so there must be another factor at play. Let us take for granted that case does block agreement. Rather, the reason default agreement is optional is perhaps because sadece projects focus, which is syntactically represented and can also block agreement, similar to case. Indeed, there is evidence that sadece can block full agreement even in simple clauses, as shown by the contrast in (16): ${ }^{10}$
a. * Iki-miz gel-di.
Two-1PL come-PST.3SG
'The two of us came.'
b. Sadece iki-miz gel-di.
Only two-1PL come-PST.3SG
'Only the two of us came.'

Bile 'even,' another focus element, can also make default agreement optional in finite clauses:
Iki-miz bile Boston-a git-ti.
two-1PL even Boston-DAT go-PST.3SG
'Even the two of us went to Boston.'

The presence of sadece is not necessary; contrastive focus can also block agreement in finite clauses, where the presence of sadece is optional in the second clause.
On kişi Harvard-a başvur-duk, ama iki-miz Harvard-a kabul edil-di.
Ten person Harvard-DAT apply-PST, but two-1PL Harvard-DAT accept AUX-PST.3SG.
'Ten of us applied to Harvard, but (only) two of us were accepted.'

Finally, if focus and case can both separately block agreement, one prediction of this account would be that there could be blocking effects, causing default agreement, even with regular pronouns if they had both focus and case. This prediction may be borne out, as shown in (19), but it was not acceptable to most of the Turkish native speakers consulted. I will propose an analysis of default agreement which could explain these facts is Focus is a phase head: ${ }^{11}$

\section{?? Sadece siz-in gide-ceğ-i-ni söyle-di.}

Only 2PL-GEN leave-FUT-3SG-ACC said-PST

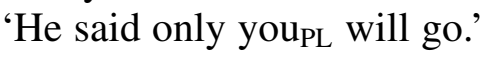

Moving onto Sakha, Kyrgyz and Altai, default agreement is surprisingly optional with complex possessors, unlike in Turkish where default agreement is required, and in Uzbek where full agreement is required. I provide illustrative examples of this with partitive subjects in (20):

$$
\begin{aligned}
& \text { a. eki-le-bis-ting biçig-i } \\
& \text { two-NUM-1PL-GEN book-3SG } \\
& \text { 'the two of us's book' }
\end{aligned}
$$
b. eki-le-bis-ting biçig-is two-NUM-1PL-GEN book-1PL 'the two of us's book'

\footnotetext{
${ }^{10}$ This observation fits with Despić (2011)'s observation on focus projections being binding domains in certain cases. Despic argues that in NP languages, a possessor can c-command out of the subject as diagnosed by binding: [ $\mathrm{X}_{\mathrm{i}}$ 's $\mathrm{N}]$... self $\mathrm{f}_{\mathrm{i}}$; but binding is blocked if the subject has a focus projection: *[only/even $\left.\left[\mathrm{X}_{\mathrm{i}}{ }^{\prime} \mathrm{s} \mathrm{N}\right]\right]$... self $\mathrm{f}_{\mathrm{i}}$, which Despic argues shows that only/even projects a focus-phrase, which then blocks c-command out.

${ }^{11}$ The optionality of the agreement, however, is something I leave open to future research. It is possible that sadece or bile can optionally adjoin as an adjunct, or take a DP as a complement, the latter of which would make DP a SpellOut domain, but the former would not. The reason it is unacceptable to most could be because it may only adjoin as an adjunct, and not as a phase head, for these people.
} 

c. ikki-em-mit aqa-ta
two-NUM-1PL father-3SG
'the two of us's father'

d. ikki-em-mit aqa-bit two-NUM-1PL father-1PL 'the two of us's father' e. eköö-büz-dün kiteb-i

two.NUM-1PL-GEN book-3SG

'the two of us's book'

f. eköö-büz-dün kiteb-ibiz two.NUM-1PL-GEN book-1PL

Sakha 'the two of us's book'
Kyrgyz

This optionality in default agreement carries onto other contexts like relative clauses; examples from Altai, Sakha and Kyrgyz are given in (21a)-(21b), (21c)-(21d) and (21e)-(21f) respectively.
a. ekilebistiñ kıçırgan biçig-i 'the book the two of us read $3 \mathrm{SG}$ '
b. ekilebistiñ kıçırgan biçig-is 'the book the two of us read $1 \mathrm{PL}$ '
c. ikkiemmit siebit at-a 'the horse the two of us ate $3 \mathrm{SG}$ '
d. ikkiemmit siebit ap-pit 'the horse the two of us ate ${ }_{1 \mathrm{PL}}$ '
e. ekö:büzdün cazgan kiteb-i 'the book the two of us $\operatorname{read}_{3 \mathrm{SG}}$ '

f. ekö:büzdün cazgan kiteb-ibiz

However, default agreement is impossible in Uzbek, as shown in (22a)-(22b), and this carries on to the relative clauses in $(22 \mathrm{c})-(22 \mathrm{~d})$ :
a. * Ikki-miz-ning kitob-i
Two-1PL-GEN book-3SG
'the two of us's book'
b. Ikki-miz-ning kitob-imiz Two-1PL-GEN book-1PL 'the two of us's book'
c. * Ikki-miz-ning kör-gan kitob-i Two-1PL-GEN saw-PTPL book-3SG 'the book the two of us saw'
d. Ikki-miz-ning kör-gan kitob-imiz Two-1PL-GEN saw-PTPL book-1PL 'the book the two of us saw'

To recap, the phenomenon of default agreement with complex possessors varies crosslinguistically. ${ }^{12}$ I provide a summary of the languages studied and their properties below:

(23) a. Obligatory default agreement with complex possessors: Turkish, Hungarian, Finnish

b. Optional default agreement with complex possessors: Kyrgyz, Sakha, Altai

c. No default agreement with complex possessors: Uzbek

3.2. ANALYSIS. I first discuss the structure of partitive subjects. Then I derive the obligatory full agreement pattern in Turkic with regular pronouns, and see what blocks agreement with complex possessors. I argue that it can be derived with two ingredients: agreement is parasitic on case and Chomsky (2001)'s weakened version of the Phase Impenetrability Condition (PIC)along with the phase status of $\mathrm{K}^{0}$ and either $\mathrm{D}^{0}$ or $\mathrm{n}^{0}$. I will provide two different solutions based on whether one accepts the presence of a D layer in the Turkic languages, in line with Bošković \& Şener (2014)'s conclusion, in order to remain agnostic.

First, I propose the pronoun in partitives is in Spec,PossP as it is the source of the non-optional agreement on the possessive suffix, as in (24). I also propose that the pronoun in APCs is located in Spec,NumP given the plurality of the lexical NP in APCs, as in (25).

\footnotetext{
${ }^{12}$ Due to space considerations I will omit default agreement in these languages with adnominal pronouns, but the agreement patterns are the same as with partitives in Sakha, Altai, Uzbek and Kyrgyz.
} 
(24)
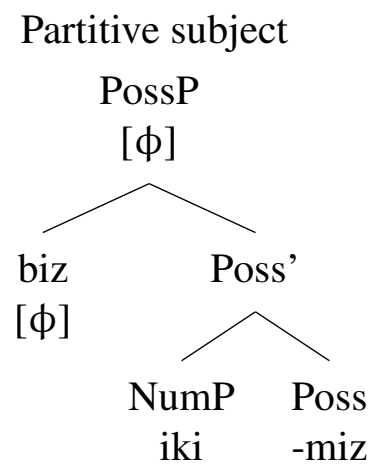

(25)

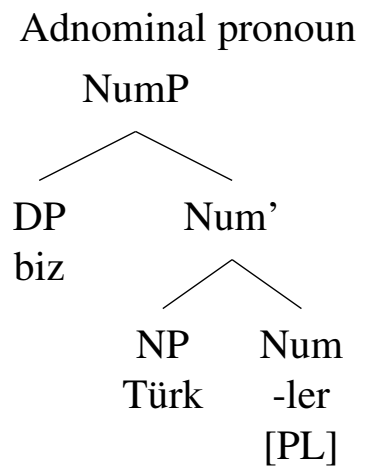

I concur with Höhn (2019) that the structure of APCs in head-final languages such as Turkish with prenominal APCs differs from that of the structure given in Höhn (2017); the pronoun in APCs is a specifier in Turkish rather than the head, unlike in English where it is the head. ${ }^{13}$

But I must make one explicit stipulation. As noted prior, the partitive subject construction biz ikimiz has a bare pronoun with possessive agreement. In an unmarked theory of genitive case, how can a pronoun be left bare if it is in some Spec position of the nominal? Here I must slightly change the definition of unmarked case in Marantz's hierarchy; it cannot be assigned in Spec position of the extended nominal domain; it can only be assigned in Spec,NP (nP to be more precise). This definition is given as follows:

Unmarked genitive case: Assigned automatically to any NP in a Spec,nP position.

We can now move onto default agreement. I take for granted that possessive structures have the same basic structure as in Alexiadou et al. (2007) and Holmberg (2017), among others, who argue that Poss is present as a functional projection containing the possessor in its specifier, as in (27). In line with Alexiadou et al. (2007), we can also assume that the possessor is base-generated in a Spec,nP position and moves up to PossP, as I schematize in (27). Genitive case has been assigned to the possessor in Spec,nP, in line with the configurational theory of case, since there is no competitor in the domain:

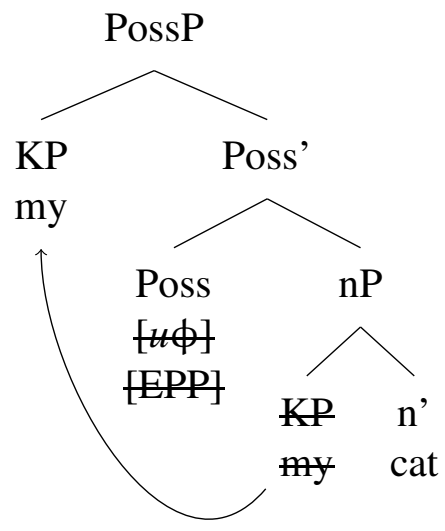

Let us derive agreement in a simple PS such as bizim kedimiz 'our cat.' $\mathrm{K}$ itself does not inherit the $\phi$-features on DP, in line with Ackema \& Neeleman (2018) who make the same point

${ }^{13}$ If Turkish APCs had the structure of APCs from Höhn (2017), this would be problematic: Höhn (2019) points out that it would imply a disharmony between PPs and VPs and the fact that APs are head-initial. 
based on independent reasons. As Holmberg (2017) also points out, this assumption is required to block agreement with quirky case-marked nominals in Icelandic. Finally, note that there are two Spell-Out domains, which I have circled. For Bošković (2011) and Despić (2015), among others, the phase head is merely the highest head in the nominal domain; $\mathrm{K}$ if there is no DP and $\mathrm{D}$ if there is no K. However, for this account to go through, I must assume that $\mathrm{K}$ and $\mathrm{D}$ are both phases, rather than just one being the phase, as is commonly assumed. ${ }^{14}$

As a result, the two Spell-Out domains are DP and PossP. However, only one of these SpellOut domains is impenetrable, in line with Chomsky (2001)'s weakened PIC, defined below: ${ }^{15}$

Phase Impenetrability Condition (weak):

In phase $\mathrm{A}$ with head $\mathrm{H}$, the domain of $\mathrm{H}$ is accessible to operations outside A only until the next (strong) phase head is merged.

Only NumP becomes inaccessible to further operations when $\mathrm{K}$ is merged. The head of the regular pronoun, D, has already inherited the number features from NumP via agreement. The Poss probe agrees with its goal, DP; though DP is the Spell-Out domain of K, Poss itself is not a phase head, and it is therefore in its search domain. This structure is given in (29), in which the impenetrable Spell-Out domain is circled in gray:

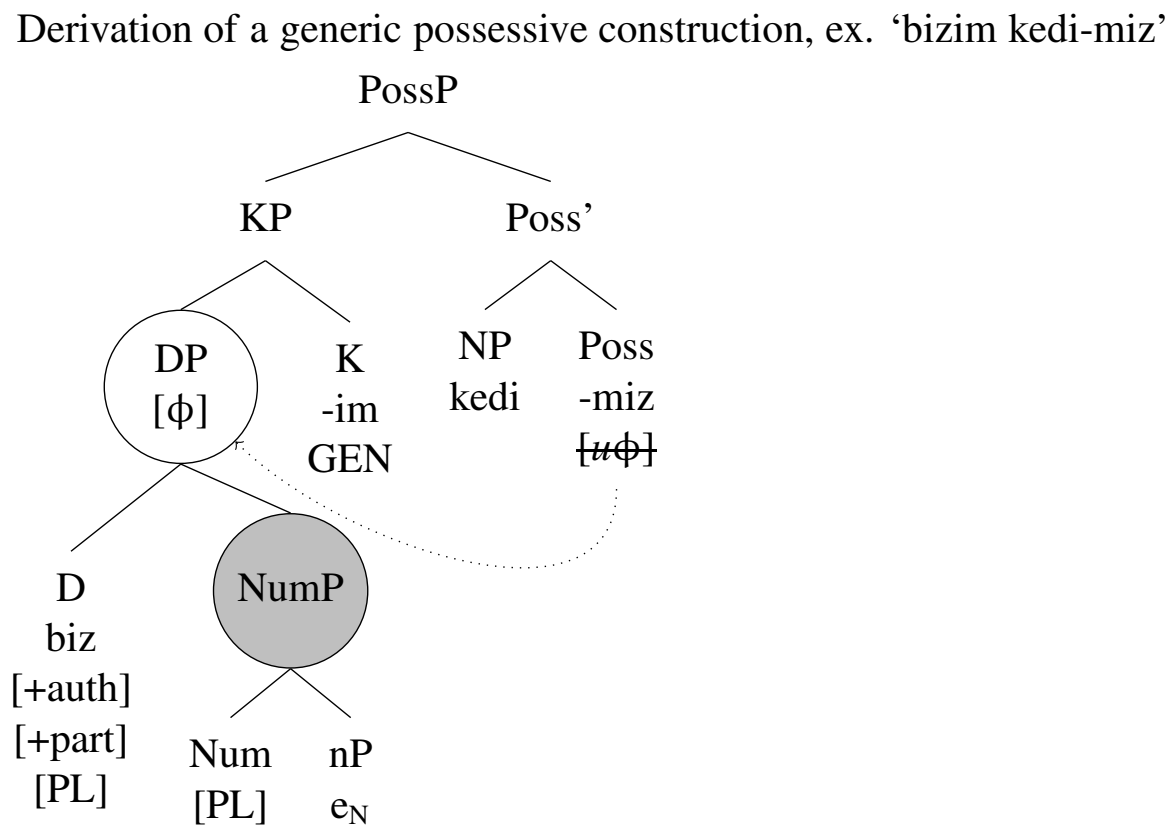

The derivation of default agreement is slightly different, but it follows immediately if we assume a weakened version of the PIC. If the AP and the pronoun in the partitive are both unable to move to Spec,DP, then they would be outside of the search space of the outer Poss probe. ${ }^{16}$

\footnotetext{
${ }^{14}$ Assuming the weakened PIC, the double phase configuration may actually be empirically advantageous; as far as I am aware existing works have assumed the stronger version of the PIC for which one phase is enough. The double phase configuration would be able to derive the same facts with the weakened PIC.

${ }^{15}$ Asarina \& Hartman (2011) argue for independent reasons that the weakened PIC should be preferred over Chomsky (1998)'s stronger condition, showing that Uyghur genitive subject licensing in subordinate clauses would violate the stronger version of the PIC, but not the weakened one.

${ }^{16}$ I will claim later in the paper that it $i s$ possible for them to move, but an assumption I must make is that they cannot do so in Turkish, in order to derive default agreement. They can obligatorily move in Uzbek, and optionally in the
} 
Agreement with a regular pronoun was possible because the DP itself had $\phi$-features to agree with. However, in both the partitive and AP construction, the bearer of $\phi$-features has been SpelledOut; the features do not pass on to DP, or whatever the maximal projection is. As a result, agreement is attempted, but it fails, triggering default agreement in the Preminger sense rather than the derivation crashing. This tree is shown in (30); the Spelled-Out domain is in gray:

Derivation of a partitive subject, ex. (biz) ikimizin kedi-si

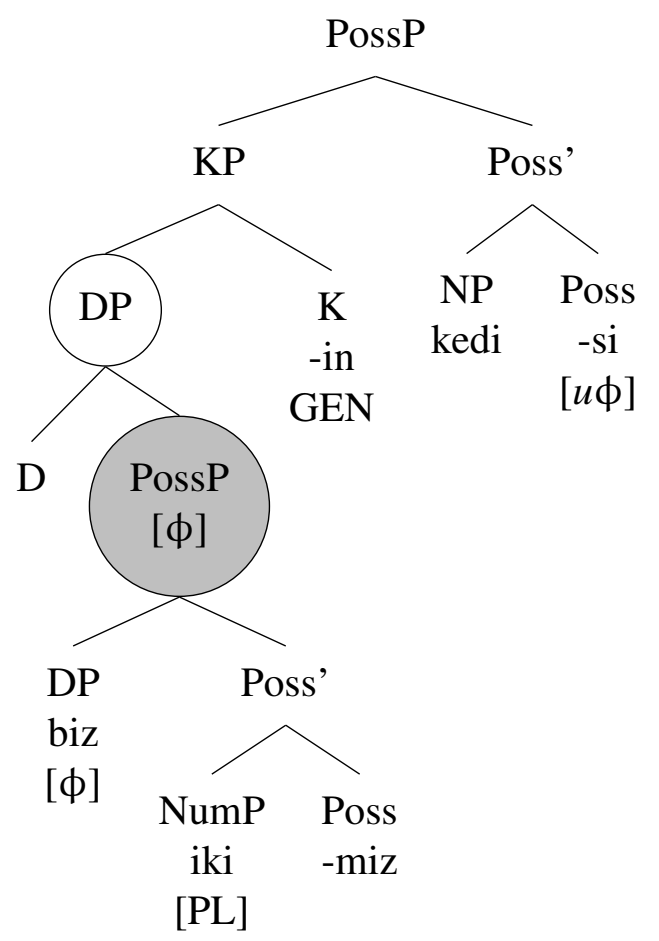

In the tree above, notice that though NumP clearly has [PL] features and PossP has the $\phi$-features from the pronoun (via agreement), none of these features have percolated up to $\mathrm{D}$, otherwise full agreement would be obtained. In the case of NumP, [PL] does not percolate as D does not agree with NumP, unlike a regular pronoun construction. On the other hand, D also does not obtain the features of its complement, PossP, despite Agree being an operation which copies $\phi$-features.

PossP's features do not percolate to D. This can be shown: when PSes with 1st person possessors agree with the matrix verb in Turkish, there is 3rd person singular agreement on the verb. The D that heads benim kedi-m "my cat' does not get the $\phi$-features from the bolded possessive suffix; if it were able to, then $1 \mathrm{SG}$ agreement would be possible in (31b), contrary to fact:
a. Benim kedim geldi. 'My cat came.'
b. * Benim kedim geldi-m. 'My cat came.'

One potential problem could be that my account could accidentally derive full agreement in (31b), via agreement with the embedded 1 SG pronoun because the PS is nominative, which does not project a KP layer to help block agreement. But the pronoun itself has genitive case, and benim kedim 'my cat' is itself a DP, so agreement with the embedded pronoun is blocked.

other Turkic languages. This might simply due to a lack of a phase-edge feature on D in Turkish, but it is optionally present in the Turkic languages where default agreement is optional, and obligatory in Uzbek. 
Full agreement in finite clauses can be derived with the weakened version of the PIC. The phase head $\mathrm{K}$ is not present if nominative case is caselessness, and it does not project a KP layer; $\mathrm{T}^{0}$ itself is not a phase head, as Citko (2014) shows, and it can therefore agree with the caseless matrix subject. In addition, the data in the subsection prior with default agreement with only can also be derived if Focus ${ }^{0}$ is a phase head, as we have already discussed. As noted above, I have left open the question of why this agreement is optional; it is possible that there are two different ways for sadece to adjoin, one of which is with a phase head and the other is an adjunct, and default agreement reflects the former while full agreement reflects the latter.

These derivations rely on the assumption that DP is the maximal projection of the nominal phrase in Turkish; it would be preferable to eliminate it. If there were another phase head in the nominal layer, this would be straightforward. One way of doing so might be to assume that the pronoun bearing $\phi$-features is base-generated deeper inside the nominal and stays there. Since Embick \& Marantz (2007) the categorizing head $\mathrm{n}^{0}$ has usually been considered to be a phase, and this would get the same results as the DP layer. However, one must assume that the pronoun is not at the edge of the nP phase, and deeper inside, so that it is not accessible to probing.

This account successfully derives default agreement in Turkish, along with Finnish and Hungarian. What remains is how to derive the optionality of default agreement in most other Turkic languages, and outright ban of default agreement in Uzbek. One can assume that the pronoun bearing $\phi$-features obligatorily moves to a Spec,DP position in Uzbek, to a phase edge position so that it is able to agree with the outer Poss probe. This process may be optional in the other Turkic languages. However, I cannot eliminate the stipulatory nature of this proposal, and I leave this to future research.

3.3. Theoretical Discussion. Default agreement is difficult to account for without further assumptions in the $\mathrm{B} \& \mathrm{~V}$ account of genitive case assignment. This analysis relies on the presence of a KP layer, put on the possessor via configurational case assignment, blocking agreement in possessive structures; it happens prior to agreement, and is not parasitic on agreement. By contrast, there is nothing to block agreement under B\&V's account of case assignment.

One potential solution under B\&V's account, which I will argue against, can be found by changing the nature of the operation Agree, which is responsible for agreement. Arregi \& Nevins (2012), among others, splits the operation of Agree into two sub-operations, Agree-Link and Agree-Copy. Agree-Link is responsible for matching the probe with its goal, and Agree-Copy may copy features between the two Agree-Linked objects. Agree-Copy can happen either within the narrow syntax or postsyntactically, but Agree-Link can only happen in the former.

Suppose that difference between default and full agreement is syntactic vs. semantic agreement; one can argue that the kind of agreement in Turkic finite clauses is semantic and not syntactic, but it must be syntactic in possessive structures. This might be due to the presence of the KP layer on the possessor. One such account is provided by Smith (2015), who attempts to derive the difference in plural agreement between American and British English; semantic agreement is possible in British English but not American (ex. the committee are here). This account could also provide an account of default agreement based on this framework, if we stipulate that Agree-Link is responsible for assigning genitive case, but Agree-Copy, which happens later in the derivation, does not, and KP blocks Agree-Copy from copying semantic features; it resorts to copying syntactic features instead.

This account makes two incorrect predictions: first, the lack of genitive case on the pronoun 
in partitives such as biz iki-miz 'the two of us' remains problematic, given that Agree-Link has not assigned genitive case to the pronoun despite agreement. More importantly, it makes an incorrect prediction with polite pronouns in Turkish, which are syntactically plural but semantically singular. If agreement in Turkish finite clauses was semantic, we would expect agreement with polite pronouns to be semantic, which is contrary to fact; it is obligatorily syntactic in both finite clauses and possessive structures, as shown below:

$$
\begin{aligned}
& \text { a. } \quad \text { Siz geldi-niz. } \\
& \text { 2PL came-POSS.2PL } \\
& \text { 'You }{ }_{\text {sg }} \text { came.' (polite) }
\end{aligned}
$$
b. Siz-in kedi-niz
2PL-GEN cat-POSS.2PL
'Your ${ }_{\text {sg }}$ cat' (polite)

One further prediction this account would have to make is that agreement in Uzbek is always semantic; since as noted prior in this section, full agreement is always required in Uzbek. But similarly to Turkish, Uzbek always has syntactic agreement with polite pronouns:

$$
\begin{aligned}
& \text { a. } \quad \text { Siz keldin-giz. } \\
& \text { 2PL came-POSS.2PL } \\
& \text { 'You } \text { sg }_{\text {g }} \text { came.' (polite) }
\end{aligned}
$$
b. Siz-ning kitob-ingiz 2PL-GEN cat-POSS.2PL$$
\text { 'Your }{ }_{\mathrm{sg}} \text { book' (polite) }
$$

To recap, the argument that case blocks agreement with complex possessors in Turkish seems to be correct; it is not clear how the $\mathrm{B} \& \mathrm{~V}$ approach would derive the same results.

4. Conclusion. Prior to concluding, I would like to point out some potential issues to this approach pointed out by Paparounas \& Akkuş (2020), who provide independent arguments for genitive case blocking agreement in Turkish, coming to the same conclusion presented here. But they also point out potential issues with the approach; for example, that the account provided here makes very specific assumptions on the nature of case assignment and its timing. I would like to point out that, as they also assume case assignment must take place before agreement, this is not such an issue after all; that is the only assumption that is needed for the argument in this paper to go through, and it is precisely the same assumption that they make as well. ${ }^{17}$

A more important issue is that they point out that the approach here is not capable for accounting for the full range of facts, noting that, for example, inflected pronouns such as bizler "we-PL" and complex reflexives also trigger default agreement, yet the approach here only discusses APCs and partitives. If we assume, following Kornfilt (2003) that such complex reflexives have a null pronoun subject with a complex structure-precisely as APCs and partitives dothat would provide a straightforward derivation of default agreement. Second, it might be plausible to think of inflected pronouns as very similar in structure to APCs, but with a null noun that agrees with the pronoun.

I have argued that deriving the existence of Turkic default agreement is straightforward if, as the empirical evidence suggests, case is responsible for blocking agreement; as in languages such as Hungarian where dative case-marked complex possessors also trigger default agreement. At the very least, this paper provides a novel empirical and theoretical argument to an ongoing debate concerning the relationship between case assignment and agreement.

\footnotetext{
${ }^{17}$ That is, with the exception of the assumption made in (26) which admittedly is not optimal. I leave it open to future research as to how this can be improved upon.
} 


\section{FPF्FT:}

Ackema, P. \& A. Neeleman. 2018. Features of person: From the inventory of persons to their morphological realization. Cambridge, MA: MIT Press.

Alexiadou, Artemis, Liliane Haegeman \& Melita Stravou. 2007. Noun Phrase in the Generative Perspective. Berlin/New York: Mouton de Gruyter.

Arregi, Karlos \& Andrew Nevins. 2012. Morphotactics: Basque auxiliaries and the structure of spellout. Dordrecht: Springer.

Asarina, A. \& J. Hartman. 2011. Genitive subject licensing in Uyghur subordinate clauses. In A. Simpson (ed.), Proceedings of WAFL 7, 17-31. Cambridge, MA: MITWPL.

Aydın, Ö. 2008. Agreement with partitive quantifiers in Turkish. In Essays on Turkish Linguistics: Proceedings of the ICTL 14. Wiesbaden: Harrassowitz Verlag

Baker, Mark. 2015. Case: Its principles and its parameters (Cambridge Studies in Linguistics). Cambridge: Cambridge University Press

Baker, Mark C. \& Nadya Vinokurova. 2010. Two modalities of case assignment: Case in Sakha. Natural Language and Linguistic Theory 28(3). 593-642.

Bittner, Maria \& Ken Hale. 1996. The structural determination of case and agreement. Linguistic Inquiry 27(1). 1-68.

Bobaljik, Jonathan David. 2008. Where's Phi? Agreement as a postsyntactic operation. In Daniel Harbour, David Adger \& Susana Béjar (eds.), Phi theory. 295-328. Oxford: Oxford University Press.

Boškovic, Željko. 2011. Rescue by PF deletion, Traces as (non)interveners, and the That-Trace effect. Linguistic Inquiry 42(1). 1-44.

Boškovic, Željko \& Serkan Şener. 2014. The Turkish NP. In P. Cabredo Hofherr \& A. Zribi-Hertz (eds.), Crosslinguistic studies on noun phrase structure and reference, 102-140. Leiden: Brill

Chomsky, Noam. 1998. Some observations on economy in generative grammar. In Pilar Barbosa, Danny Fox, Paul Hagstrom, Martha McGinnis \& David Pesetsky (eds.), Is the best good enough?. 115-128. Cambridge, MA: MIT Press.

Chomsky, Noam. 2000. Minimalist inquiries: The framework. In Roger Martin, David Michaels \& Juan Uriagereka (eds.), Step by step: Essays on minimalist syntax in honor of Howard Lasnik. 89-156. Cambridge, MA: MIT Press.

Citko, Barbara. 2014. Phase theory: an introduction. Cambridge: Cambridge University Press.

Despić, Miloje. 2011. Syntax in the absence of Determiner Phrase. Storrs, CT: University of Connecticut dissertation.

Despić, Miloje. 2015. Phases, reflexives and definiteness. Syntax 3. 201-234.

Embick, D. \& A. Marantz. 2007. Architecture and blocking. Linguistic Inquiry 39(1). 1-53. 
Höhn, Georg. 2017. Non-possessive person in the nominal domain. Cambridge, UK: University of Cambridge dissertation.

Höhn, Georg. 2019. A word order typology of adnominal person. Unpublished manuscript.

Holmberg, Anders. 2017. Case and agreement in possessive noun phrases in mainly English, Swedish, and Finnish. Unpublished manuscript.

Ince, Atakan. 2008. On default agreement in Turkish. Unpublished manuscript.

Kornfilt, Jaklin. 2003. Local and long-distance reflexives in Turkish. In Uwe Junghanns \& Luka Szucsich (eds.), Syntactic structures and morphological information, 129-215. Berlin: Mouton de Gruyter.

Kornfilt, Jaklin \& Omer Preminger. 2015. Nominative as no case at all: An argument from raising-to-ACC in Sakha. In Andrew Joseph \& Esra Predolac (eds.), Proceedings of the 9th Workshop on Altaic Formal Linguistics (WAFL 9) (MIT Working Papers in Linguistics 76), 109-120. Cambridge, MA: MITWPL.

Levin, Theodore \& Omer Preminger. 2015. Case in Sakha: Are two modalities really necessary? Natural Language \& Linguistic Theory 33(1). 231-250.

Marantz, Alec. 1991. Case and licensing. In Germán Westphal, Benjamin Ao \& Hee-Rahk Chae (eds.), Eastern states conference on linguistics, 234-253. Cornell University, Ithaca, NY: Cornell Linguistics Club.

Paparounas, Lefteris \& Faruk Akkuş. 2020. The Anaphor Agreement Effect in the nominal domain: Evidence from Turkish. Proceedings of the Linguistic Society of America 5(1). 484-498. https://doi.org/10.3765/plsa.v5i1.4725.

Preminger, Omer. 2014. Agreement and its failures (Linguistic Inquiry Monographs 68). Cambridge, MA: MIT Press. 